\title{
FABRICACIÓN DE PUNTAS DE PROYECTIL EN LOS NIVELES TARDÍOS DE LA CUEVA TRES ARROYOS 1, TIERRA DEL FUEGO ${ }^{1}$
}

CONSUELO HUIDOBRO M.

\section{RESUMEN}

Se presentan los resultados de un análisis tecnológico de las cadenas operativas de reducción bifacial representadas en los niveles estratigráficos I, II, III y IV del sitio Tres Arroyos 1, fechado entre los 1.350 y los 135 años AP. Estas se orientaron exclusivamente a la manufactura de puntas de proyectil de los tipos conocidos como Fell IV y V, que se encuentran representados de forma diferencial a lo largo de la secuencia de ocupación. Si bien se registran diferentes conductas asociadas a la manufactura de estos instrumentos, también son observables ciertas recurrencias, tales como el orden de ejecución de las secuencias operativas y la tendencia a escoger soportes de dimensiones cercanas a las del producto final. Se discuten las implicancias de los cambios y similitudes observados a lo largo de la secuencia de ocupación del sitio.

PALABRAS CLAVE: tecnología lítica, reducción bifacial, punta de proyectil, Tierra del Fuego, cazadores terrestres.

\section{PROJECTILE POINT MANUFACTURE IN THE LATE STRATIGRAPHIC LEVELS AT TRES ARROYOS 1 CAVE, TIERRA DEL FUEGO}

\section{ABSTRACT}

We present the results of a technological analysis focused in the bifacial reduction sequences represented in the stratigraphic levels I, II, III and IV of the Tres Arroyos 1 archaeological site, dated between 1.350 and 135 years BP. These sequences are focused in the manufacture of projectile points, known as Fell IV and $\mathrm{V}$ which are differentially represented across the occupational sequence. Even though some differences in behaviors associated to the manufacture sequences are registered, some recurrences are observed as well, such as the order of execution of operational sequences, and the tendency to choose blanks whose sizes are similar to the sizes of the finished product. The implications of observed differences are discussed.

KEY WORDS: lithic technology, bifacial reduction method, projectile point, Tierra del Fuego, terrestrial hunter gatherers.

1 Los resultados presentados en este artículo forman parte de la Memoria de Título de la autora, realizada en el marco del proyecto Fondecyt 1060020.

Arqueóloga, Universidad de Chile. E-mail: consuelo.huidobro@gmail.com 


\section{INTRODUCCIÓN}

El Holoceno tardío en el norte de Tierra del Fuego presenta un registro arqueológico relativamente rico y variado, que ha sido interpretado como evidencia de una etapa de ocupación efectiva de la isla (Borrero 1989-90), y vinculado a las manifestaciones culturales Selk'nam y pre Selk'nam (Massone et al. 1993). Las puntas de proyectil bifaciales pedunculadas con aletas son características de este periodo, y se encuentran ampliamente distribuidas en el norte y centro de la isla, siendo común su hallazgo superficial y en menor medida, su registro en estratigrafía en contextos fechados dentro de los últimos 2000 años. Entre estos se encuentra el sitio Cabeza del León 1, ubicado cercano a la Bahía San Sebastián, dónde se hallaron dos puntas tipo Fell IV (ver más adelante) en el componente más antiguo (con una fecha de $1.100 \pm 25 \mathrm{AP}$ ) y dos tipo Fell V en el componente más reciente, sin fecha directa (Borrero 1979). Otros sitios fechados en los que se encuentran este tipo de artefactos son Punta María 2 y San Genaro 1 en la costa atlántica, con fechas de $300 \pm 10$ y $1.070 \pm 80$ AP respectivamente (Borrero 1986, Horwitz 1995); Laguna 12 en los cascos de las estancias Florentina y Dos Marías, fechado en 310 \pm 70 AP (Massone et al. 1993); y Marazzi 2 sector 2 en Bahía Inútil, con una fecha de $910 \pm 70$ AP (Morello et al. 1998). Estas puntas presentan además una importante variabilidad morfológica que va más allá de las distinciones tipológicas establecidas para el continente.

En este trabajo, realizamos un estudio de las cadenas operativas de manufactura de estos artefactos, representadas en el sitio Tres Arroyos 1, con miras a evaluar su variabilidad a nivel intra sitio, y a explorar de qué forma los métodos de talla pueden vincularse a las diferencias y similitudes morfológicas registradas para estos tipos de punta de proyectil.

\section{ANTECEDENTES Y PROBLEMÁTICA}

Las puntas de proyectil en Tierra del Fuego presentan una importante variabilidad morfológica que no ha sido descrita sistemáticamente desde el punto de vista tipológico, si bien en ciertos casos se hace referencia a la clasificación elaborada por Bird (1993) para Patagonia continental meridional, en particular en cuanto a los llamados tipos Fell o
Bird IV y V (e.g Massone et al. 1993). Esto último en concordancia con ciertas similitudes morfológicas observadas a ambos lados del estrecho, particularmente entre las puntas Fell V, también conocidas como tipo "Ona" (Bird 1993). Ambos tipos de punta de proyectil corresponden a puntas pedunculadas con aletas que difieren principalmente en sus tamaños (Figura 1). Mención aparte merecen las puntas "tipo yámana", denominación que parece haber sido consagrada por el uso, posiblemente en base a las descripciones de Junius Bird de los contextos de Canal Beagle (Bird 1938). Estas corresponden a puntas triangulares, en las que el pedúnculo y las aletas se manufacturan por muescas obtenidas desde la base (Morello 2005b).

Los estudios vinculados a estos artefactos, se han enfocado en dos temas principales, asociados ambos a la evaluación de su variabilidad morfológica. Por un lado, está el mencionado problema de su distribución espacial, particularmente considerando que ésta incluye un área bastante amplia en la que existen hitos que han sido considerados como potenciales barreras biogeográficas para los grupos humanos, tales como el Estrecho de Magallanes o el río Santa Cruz (Franco y Borrero 2003, Franco et al. 2005, Franco et al. 2009). Si bien el uso de la terminología de Bird se hace con una intención descriptiva, y no necesariamente con implicancias histórico culturales, la amplia distribución de estos tipos morfológicos podría corresponder a un patrón de diseño común, y sin duda debe ser evaluada utilizando múltiples líneas de evidencia. Destacan los estudios que dan cuenta de la variabilidad morfológica utilizando análisis de componentes principales y

A)
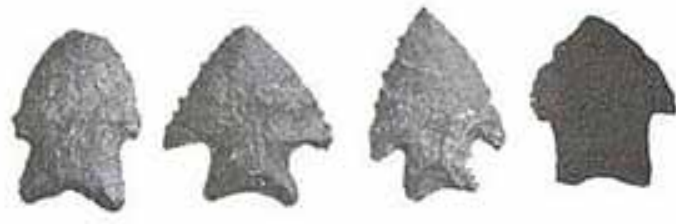

B)
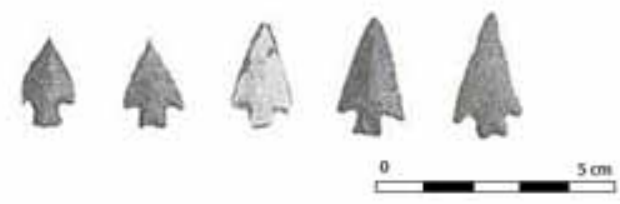

Fig. 1. A) Puntas de proyectil Bird IV B) Puntas de proyectil Bird V. Tomado de Bird 1993: 41-43. 
que recientemente han incorporado otras variables y técnicas analíticas, incluyendo el análisis de microdesgaste y la morfometría geométrica (Franco y Borrero 2003, Franco et al. 2005, Franco et al. 2009). En el caso de las puntas de Tierra del Fuego versus las continentales se han establecido algunas diferencias en cuanto a la proporción de materias primas utilizadas (mayoritariamente dacita en la Isla Grande, versus $\mathrm{RGFO}^{2}$ en Magallanes y en Santa Cruz), y a algunas características morfológicas, ya que en la isla las puntas presentarían cuellos más delgados, pedúnculos más delgados y cortos, limbos más largos, y espesor más importante en el limbo en relación al cuello (Franco y Borrero 2003).

Por otro lado, está el problema de explicar la variabilidad entre las puntas tipo IV y V. Inicialmente Bird (1993) consideró que sus diferencias se correlacionaban con distintos periodos histórico culturales, en su conocida secuencia para Patagonia Continental. No obstante, se ha registrado la contemporaneidad de ambos diseños en distintos contextos arqueológicos, al menos en el continente (Gomez Otero 1987, Massone 1979). De acuerdo a Norma Ratto (1991, 1994), ciertas diferencias observadas entre los tipos se asociarían a distintos requerimientos funcionales, sin que por ello exista una correlación unívoca entre un "tipo" y una función específica. Diferentes atributos morfológicos y métricos observados, se relacionarían con las necesidades de enmangue, fuerza necesaria para la penetración y grado de aerodinamia, que dependen de la función que el artefacto desempeñe, como punta de flecha, punta de lanza arrojadiza o punta de arma de mano (Ratto 1991, 1994, 2003). En esta línea, las diferencias registradas tipológicamente entre las puntas Fell IV y V se deberían a que están diseñadas para cumplir distintos conjuntos de funciones, y por lo tanto no deberían tener implicancias culturales (Ratto 1994). En particular, entre las puntas Fell IV se han reconocido características adecuadas para funcionar dentro de distintos sistemas técnicos, incluyendo como puntas de lanza arrojadiza y puntas de arma de mano; mientas que en el caso de las Fell V, se han reconocido predominantemente características adecuadas para funcionar como punta de flecha (Ratto 1994). Asimismo, en el caso particular de Tierra del Fuego, el análisis de sitios de la localidad

2 Rocas de Grano Fino Oscuro, sensu Charlin 2005 de Rancho Donata mostró la presencia de distintos grupos de punta de arma, presentando características diferenciales, adecuadas para funcionar como flechas, punta de lanza arrojadiza o no proyectiles (Ratto 1991).

La variabilidad morfológica de estos artefactos se ha evaluado por lo tanto de diferentes formas, otorgándosele distintas connotaciones. Considerando que la forma final de un artefacto es resultado de un proceso complejo, en el que están involucrados su manufactura, funcionalidad, uso y mantención de la vida útil, y alteraciones postdepositacionales entre otros (Inizan et al 1995), en este trabajo, la problemática se aborda desde la reconstrucción de los procesos de manufactura de estos artefactos, dentro de una perspectiva tecnológica, para el caso específico del sitio Tres Arroyos 1, Tierra del Fuego. Este tema ha sido previamente tratado por Nami (1987, 1988), principalmente a través de datos experimentales, aunque en algunos casos contrastados con el análisis del material arqueológico. Con esta información elabora un modelo para las cadenas operativas de manufactura de artefactos bifaciales, lo que permitiría la identificación de diferentes estadios de confección y de productos efectivamente terminados en el registro, además de acceder eventualmente a los conocimientos técnicos involucrados en su manufactura. En este trabajo sin embargo, no pretendemos elaborar modelos generales, sino que identificar los procesos de manufactura específicos del contexto de estudio, intentando discriminar decisiones tecnológicas recurrentes. Por ello, nos valemos exclusivamente de datos arqueológicos, como se verá a continuación.

Creemos que el problema de la evaluación de la variabilidad artefactual puede ser abordado en forma fructífera desde una perspectiva tecnológica, considerando que toda actividad de modificación o transformación de una materia prima, como es la manufactura de un instrumento lítico, involucra la concepción y la ejecución de un proyecto (Inizan et al. 1995). Esto se relaciona con distintos elementos, entre los que se encuentran los conocimientos aprendidos y habilidades técnicas que entran en juego con una serie de factores contextuales, dependientes o independientes del artesano, o conocidos o desconocidos por él (Pelegrin 1991, Pigeot 1991). Una de las implicancias de esto para el caso que nos ocupa es que el proceso de talla lítica puede 
ser conducido de múltiples formas en relación con distintos comportamientos aprendidos, preferencias personales, disponibilidad de materias primas, etc., aún si se buscan objetivos similares. Debido a ello, la reconstrucción detallada de las cadenas operativas y la puesta en evidencia de los factores involucrados en la concepción y ejecución del proyecto que involucran, son datos fundamentales a la hora de describir y explicar la diversidad morfológica de un conjunto artefactual.

En esta línea, y con miras a aportar a la discusión previamente descrita, nos propusimos evaluar la variabilidad de esquemas de reducción bifacial ${ }^{3}$ representados en el sitio Tres Arroyos 1 ¿Las diferencias morfológicas y métricas se asocian a distintas operaciones de manufactura?¿Encontramos recurrencias en las formas de manufactura, o existen distintos procedimientos para obtener instrumentos de morfologías similares? Para responder a estas preguntas, el análisis se orientó a la descripción de las cadenas operativas, los métodos y técnicas de talla (sensu Inizan et. al 1995) y las características de los productos buscados.

\section{EL SITIO TRES ARROYOS 1}

Tres Arroyos 1 se ubica en el Cerro de los Onas, $10 \mathrm{~km}$ al sureste de San Sebastián (figura 2). Forma parte de una localidad arqueológica en la que se han ubicado varias ocupaciones pre Selk'nam y Selk'nam, tanto en los abrigos del cerro como en los faldeos y sectores adyacentes, que ha sido interpretada como un posible lugar de reunión (Massone et al. 1993, Massone 2009). Corresponde a una cueva emplazada en la parte inferior de la ladera norte del cerro, con la entrada ubicada hacia el noroeste, a una altura de 92 m.s.n.m. El sitio ha sido excavado varias veces, primero por Earl Saxon quien realizó un sondeo y obtuvo un fechado sobre carbón, y posteriormente en forma sistemática por Mauricio Massone y su equipo (Massone et al. 1993, Massone 2004). Se identificaron seis niveles estratigráficos, de los cuales el seis se asocia a eventos paleontológicos y el cinco a ocupaciones

3 Consideramos "reducción bifacial" toda actividad de talla que involucra a modificación de un soporte por ambas caras con el objetivo de obtener una determinada morfología, esto es, como un tipo particular de "façonnage" (Inizan et al. 1995).

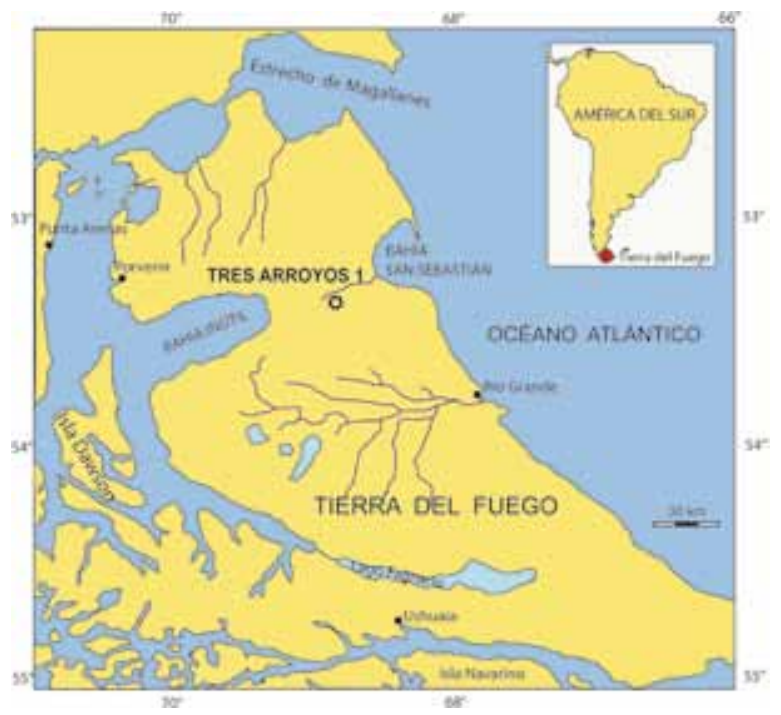

Fig. 2. Ubicación del sitio Tres Arroyos 1

humanas con fechas del orden de los ca. 10.600 AP, correspondientes a las primeras evidencias de presencia humana en la isla. Estas últimas no fueron incluidas en el análisis.

Los estratos restantes corresponden a sedimentos arenosos de origen eólico asociados a restos arqueológicos que representan al menos cuatro eventos de ocupaciones humanas adscritas al Holoceno Tardío (Massone et al. 1993). Los niveles IV y III tienen fechas de $1.350 \pm 50$ y $700 \pm$ 70 años AP respectivamente, mientras que al nivel I le corresponde una fecha de $135 \pm 85$ AP realizada por Earl Saxon (Borrero 2003: 88).

El material lítico incluye raspadores frontales pequeños como artefacto dominante, diferentes tipos de puntas 4 (Figura 3), y en menor medida, raederas laterales y cuchillos, por lo general manufacturados sobre lascas (Massone et al. 1993). Dominan las materias primas silíceas, seguidas por los basaltos, lutitas y calcedonias. Resulta importante destacar que en los niveles IV y III las puntas corresponden al tipo Periodo IV, mientras que en los niveles más recientes éstas serían reemplazadas por las puntas más pequeñas tipo "Ona" (Massone et al. 1993).

4 En el sitio se reconocieron solamente puntas pedunculadas con aletas, pequeñas y grandes, que se clasificaron como Bird V y IV. 


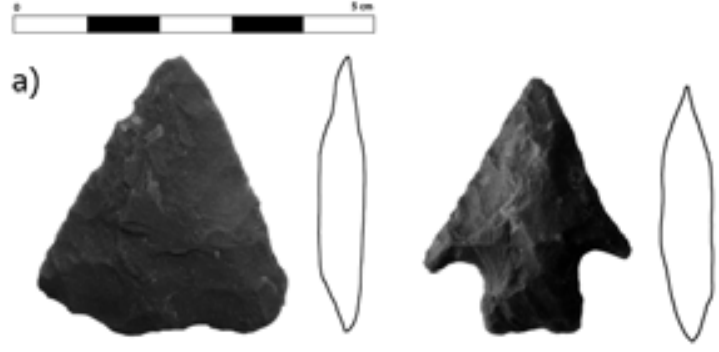

b)
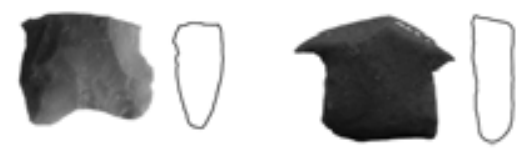

c)

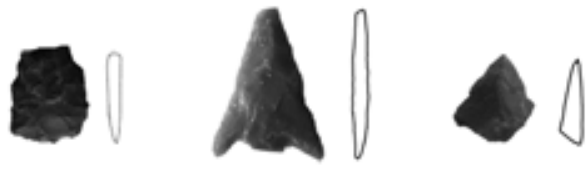

Fig. 3. Puntas bifaciales y preformas recuperadas en Tres Arroyos 1 a) Piezas analizadas en la figura 8 , b) porciones proximales, c) de tamaño pequeño (tipo "Ona")

\section{MATERIALES Y MÉTODOS}

Se trabajó con un total 1164 artefactos, de los cuales sólo aquellos asociados a cadenas operativas de reducción bifacial fueron analizados en detalle ( $n=465)$. La metodología utilizada fue la misma que en trabajos previos (Huidobro, en prensa).

Se separó el material por variedad de materia prima y procedencia estratigráfica, de acuerdo a los criterios de homogeneidad relativa en color y granulometría, presencia de cristales y otras inclusiones, similitud en pátinas u otro tipo de alteración, grado de transparencia y lustre (Jackson 2002, Ramos y Merenzon 2004, Andrefsky 2009). Las materias primas fueron además caracterizadas en base a su calidad para la talla (Aragón y Franco 1997). Las agrupaciones resultantes fueron tratadas como "nódulos analíticos míninos" (Larson y Kornfeld 1997, Andrefsky 2009), es decir, en forma operativa, como un número mínimo de eventos individuales de talla. A continuación se seleccionaron para el análisis aquellos conjuntos que presentaran evidencias de actividades de reducción bifacial, a través de la identificación de productos (bifaces) o subproductos (lascas de talla bifacial) de la misma. Las agrupaciones de materia prima así definidas fueron objeto de un análisis detallado, separando entre piezas bifaciales en las que la última extracción, obviando el retoque marginal, corresponde a un negativo, y lascas y fragmentos resultantes de la talla de un bifaz, en las que la última extracción corresponde a un positivo (Soressi 2002, Soressi y Geneste 2006).

Para el caso de los desechos de talla, se registraron atributos vinculados a la segregación de etapas de las cadenas operativas, la identificación de ciertas recurrencias en los métodos de talla, y la determinación de las técnicas de talla más probables (Pelegrin 2000). Un elemento importante fue el registro del número, sentido y dirección de los negativos en el anverso.

Para el caso de las piezas bifaciales se realizaron esquemas diacríticos, dibujos esquemáticos que consignan la secuencia de extracciones, registrándose su número, orden y sentido (Inizan et al. 1995, Morello 2005). La información obtenida, se organizó en base al reconocimiento de secuencias operativas, conjuntos de extracciones con una misma consecuencia tecnológica (Richter 2001). Estas fueron descritas en base al orden de las extracciones a nivel de las distintas caras (orden bifacial), a nivel de una misma cara (orden bilateral) y la técnica probable de obtención (percusión dura, blanda, presión). Además, se registraron algunas de las variables utilizadas por Ratto $(1991,2003)$ para la asignación funcional de cabezales líticos. Las variables elegidas fueron: simetría de los lados, simetría de la sección transversal y área del limbo (vinculados a la aerodinamia o capacidad del proyectil de mantener una trayectoria de vuelo), ángulo del ápice (asociado a la capacidad de penetración) y ancho de cuello y pedúnculo o base (asociado al enmangue).

Una vez que se determinaron los objetivos y los métodos de reducción bifacial, los artefactos bifaciales fueron clasificados de acuerdo a su posición en la secuencia de reducción, basándonos en la división cualitativa entre obtención del soporte, esbozo (instalación del volumen bifacial) y terminación (instalación de una morfología de contorno determinada) (Inizan et al. 1995), que consideramos pertinente para la mayoría de las cadenas operativas de reducción bifacial, incluyendo el caso de estudio. Asimismo, se adaptaron algunos elementos del modelo elaborado por Nami a partir de las propuestas de Erret Callahan (Nami 1987, 1988), si bien los 
criterios métricos de adscripción de las piezas a uno u otro estadio no fueron utilizados. De esta forma, consideramos:

Estadio 1: Soporte no modificado

Estadio 2: Volumen bifacial instalado en forma parcial por la creación de un borde diedro a ser utilizado como plataforma de percusión

Estadio 3: Volumen bifacial completamente instalado lográndose secciones biconvexas, lo que en ciertos casos va acompañado de un adelgazamiento del soporte.

Estadio 4: Modificación del contorno de la pieza con el propósito de obtener una morfología determinada (por ejemplo, obtención de un limbo triangular, aletas y pedúnculo). Las piezas clasificadas en este estadio, se consideraron como preformas no terminadas.

Estadio 5: Producto terminado

\section{RESULTADOS}

\section{Caracterización general del conjunto lítico}

La mayoría de los artefactos líticos se encuentra en los niveles III y IV (23 y 36\% del total respectivamente), no obstante la composición de los conjuntos es relativamente similar a lo largo de la secuencia. Hay un amplio predominio de los desechos de tamaño pequeño, principalmente fragmentos $(n=423,36,34 \%)$ y desechos de retoque o reavivado ( $n=322,27,66 \%)$. Las lascas también se encuentran representadas ( $\mathrm{n}=130,11,16 \%)$, aunque en la mayoría de los casos se trata de lascas de reducción bifacial ( $n=89,7,64 \%$ del total) y no de derivados de núcleo. Los instrumentos sobre lasca incluyen 42 casos, siendo mayoritarios los raspadores frontales con retoque directo, y en menor medida, las raederas laterales. Los instrumentos bifaciales por su parte, agrupan 21 casos. Por otro lado, la gran mayoría de los artefactos (87\%) no presenta corteza, siendo minoritarios los casos de lascas con menos de $50 \%(\mathrm{n}=29,2,49 \%)$, con más de 50\% $(\mathrm{n}=16$, $1,37 \%)$ y con $100 \%$ de corteza en el anverso $(n=7$, $0,6 \%)$. Esto, junto con las mencionadas frecuencias de las categorías artefactuales, indica un predominio de las actividades de confección y manutención de instrumentos en el sitio, por sobre otras como la producción de lascas u otras asociadas a las primeras etapas de las cadenas operativas líticas. La mayoría de las materias primas representadas habrían ingresado por lo tanto, bajo forma de soportes con bajo o nulo porcentaje de corteza, o como instrumentos retocados que son reactivados en el sitio.

En cuanto a las materias primas utilizadas, tal como se reconoció previamente (Massone et al. 1993), predominan distintas variedades de rocas silíceas, dentro de las cuales podemos reconocer un grupo probablemente correspondiente a rocas ígneas de grano fino félsicas ( $\mathrm{n}=156,13,37 \%)$; y un segundo a variedades de sílice $(n=290,33,48 \%)$. Estas rocas incluyen 14 variedades distribuidas en forma similar a lo largo de la secuencia de ocupación, de calidades para la talla variables, de regular a muy buena. Las RGFO representan el segundo grupo importante, con un 30,75\% ( $n=356)$, y agrupan 6 variedades de roca, también de calidad regular a muy buena. De estas, la materia prima 2 constituye el tipo más abundante del sitio (cerca del 20\% del total), si bien esto puede deberse a que su homogeneidad macroscópica puede enmascarar varios eventos de talla individuales. El porcentaje restante incluye cuarcitas, madera fósil y rocas tipo laja. La mayoría de estas rocas se encuentra disponibles en fuentes secundarias, resultado del acarreo glacial, en bermas, paleoplayas o terrazas marinas, en los sectores de Bahía Inútil (unos $30 \mathrm{~km}$ al oeste del sitio) y Bahía San Sebastián (aproximadamente $10 \mathrm{~km}$ al este de Cerro de los Onas). Por otro lado, también es posible encontrar acumulaciones de guijarros en frentes de morrenas y en áreas erosionadas a lo largo de la sierra Carmen Sylva y en el sector de Cachimba, más cercanos al sitio (Jackson 2002).

\section{Materias primas y eventos de talla bifacial}

Por su parte, la actividad de reducción bifacial se encuentra representada en todos los niveles estratigráficos. La importancia relativa de esta actividad se midió utilizando el índice propuesto por Aschero y Hocsman (2004), que considera el porcentaje de desechos de talla bifacial en relación al total de los desechos de talla identificables, excluyendo los fragmentos sin talón. Además, se calculó el porcentaje de artefactos asociados a cadenas operativas de reducción bifacial incluyendo los fragmentos, utilizando para su adscripción el criterio de homogeneidad de materia prima y procedencia estratigráfica. Estos porcentajes se compararon con 
la frecuencia relativa de instrumentos bifaciales por nivel (tabla 1).

La reducción bifacial es minoritaria, no obstante se encuentra relativamente bien representada en los niveles III y IV (si bien se observan discrepancias en los valores de los porcentajes calculados), disminuyendo en las ocupaciones más tardías. Cabe destacar que en el nivel II se detectaron muy pocas evidencias de esta actividad en términos absolutos. Además se observan discrepancias entre la importancia de la actividad de talla bifacial in situ (medida por los dos primeros valores obtenidos) y el porcentaje de instrumentos bifaciales en relación a otros, ya que éste último es mayor. Esto puede explicarse por el ingreso al sitio de instrumentos terminados o en estados avanzados de reducción (porciones basales de cabezales líticos que son reemplazados, puntas que son reactivadas in situ o que ingresan para ser utilizadas para otras funciones, etc). Por otro lado, como se verá más adelante, en las ocupaciones más recientes disminuye el tamaño de los instrumentos bifaciales confeccionados, con lo que las secuencias de reducción se hacen más cortas, y los subproductos de talla presentan tamaños muy pequeños (mucho menor a $1 \mathrm{~cm}$ ), por lo que pudieron no ser recuperados en su totalidad en la excavación, y son prácticamente indistinguibles de los desechos de retoque de otros tipos de instrumento. Esto también puede estar influyendo en las discrepancias mencionadas, así como en la disminución de la importancia de la talla bifacial en los niveles I y II.

Las materias primas utilizadas para la talla bifacial, son similares a las utilizadas para otras operaciones de talla (Figura 4). No obstante, se observa que se selecciona una menor variedad de rocas para estas operaciones, incluyendo rocas ígneas félsicas, sílices y RGFO. El único atributo que podría dar cuenta de una selección de materias primas, por cuanto es el único que se repite en los distintos subgrupos, es la textura, que se vincula directamente con la calidad para la talla (Aragón y Franco 1997). La mayoría (81\%) de las rocas seleccionadas para la talla bifacial presentan una textura de grano fino homogénea, y por lo tanto tienen una buena calidad para la talla, mientras que sólo un $38 \%$ de las rocas usadas para operaciones de desbaste o confección de instrumentos unifaciales presenta esta cualidad.

Un total de 465 artefactos corresponden a variedades de materia prima (nódulos analíticos mínimos) que se utilizaron en operaciones de reducción bifacial, si bien no en todos los casos de forma exclusiva (tabla 2): sólo 189 artefactos (incluyendo algunos fragmentos) pueden asociarse de forma certera a este tipo de operación a partir de criterios intrínsecos de las piezas, mientras que el número restante presenta atributos poco diagnósticos que en ciertos casos podrían integrarse a las primeras fases de la talla bifacial o bien corresponden a otros tipos de operación ejecutadas en la misma variedad de materia prima. Al comparar las frecuencias de categorías artefactuales por variedad de materia prima y niveles estratigráficos, se observa que en la mayoría de los casos (14 agrupaciones), las materias primas debieron ser ingresadas como soportes que se integraron directamente a cadenas operativas de talla bifacial; mientras que como mínimo en cuatro casos, ingresarían bajo formas que se desbastan in situ, obteniéndose a su vez distintos productos que se integran a diferentes tipos de cadena operativa, ya sea de reducción bifacial, o para la manufactura de otros instrumentos sobre lasca, tales como raspadores y raederas.

Del total de 18 agrupaciones obtenidas, 6 están compuestas únicamente por desechos, que es posible interpretar como eventos de talla bifacial en los que el instrumento obtenido fue transportado fuera

Tabla 1. Importancia relativa de la actividad de reducción bifacial en el sitio.

\begin{tabular}{|c|c|c|c|}
\hline Nivel & $\begin{array}{c}\text { Indice Aschero y Hocsman } \\
\text { (sin fragmentos) }\end{array}$ & Indice incluyendo fragmentos & Instrumentos bifaciales \\
\hline I & $7,01 \%$ & $9,16 \%$ & $75,00 \%$ \\
\hline II & $8,30 \%$ & $8,19 \%$ & $0,00 \%$ \\
\hline III & $12,50 \%$ & $13,87 \%$ & $12,50 \%$ \\
\hline IV & $8,95 \%$ & $14,90 \%$ & $50,00 \%$ \\
\hline $\begin{array}{c}\text { Todos (considerando } \\
\text { limpiezas de perfil) }\end{array}$ & $14,78 \%$ & $12,50 \%$ & $24,50 \%$ \\
\hline
\end{tabular}




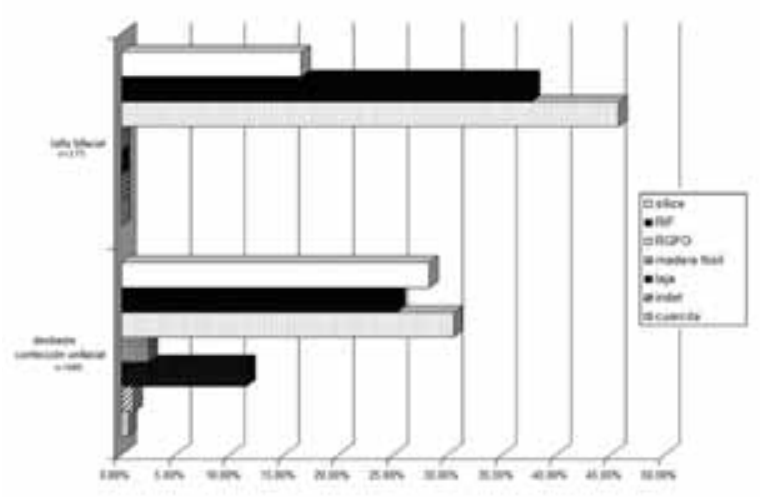

Fig. 4. Frecuencia relativa de materias primas utilizadas en actividades de desbaste y confección de instrumentos unifaciales, versus las utilizadas en actividades de reducción bifacial.

del sitio ${ }^{5}$. Además se registraron 12 agrupaciones de desechos asociados a instrumentos bifaciales, ya sea preformas o instrumentos interpretados como productos finales, los que en algunos casos corresponderían a eventos de manufactura de un producto descartado in situ por accidentes de talla, y en otros, a eventos de reactivación de una punta

5 Aunque lógicamente también hay que tener en cuenta los potenciales problemas de muestreo a la hora de interpretar las frecuencias artefactuales. posteriormente descartada. De entre los accidentes de talla identificados en los instrumentos, predominan las fracturas por flexión (7 casos), seguidos de la acumulación de bisagras (3 casos) y negativo de talón espeso (1 caso). Adicionalmente, en 3 casos se registraron fracturas posiblemente asociadas al impacto, y en otros 3 , fracturas indirectas transversales que no pudieron asociarse a una causa probable. En los casos restantes no se registraron fracturas ni accidentes de talla.

\section{Esquemas diacríticos}

Se confeccionaron 21 esquemas diacríticos correspondientes a la totalidad de los instrumentos bifaciales registrados en el sitio. Estos evidencian distintos momentos de las cadenas operativas de manufactura de las puntas tipo Fell IV y V. Únicamente encontramos dos piezas que no caben dentro de estas categorías. Una de ellas corresponde a un fragmento mesial trabajado por percusión blanda y presión, mientras que la otra se encuentra trabajada por percusión dura. Esta última (Figura 5) es interesante, ya que evidencia conductas distintas a las otras piezas en relación a los primeros estadios de reducción. El soporte no es visible, aunque al presentar corteza en uno de los extremos, podría

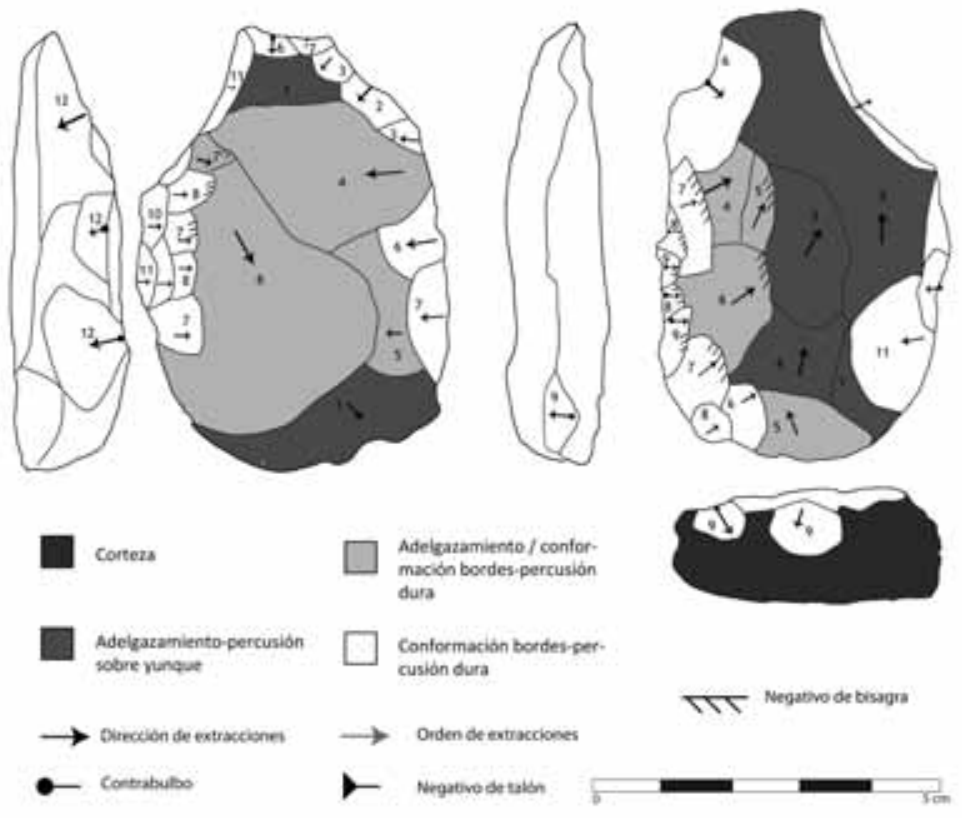

Fig. 5. Pieza bifacial trabajada por percusión dura 
tratarse de un guijarro o una lasca primaria o secundaria de dimensiones grandes. Inicialmente habría sido trabajada por percusión sobre yunque, mientras que las extracciones siguientes se ejecutarían por percusión dura, en al menos dos series trabajando ambas caras en forma separada. Estos procedimientos posibilitan la conformación de un borde a través de lascados secantes, luego de reducir el espesor de la pieza. Finalmente, no se logra la conformación completa de un borde diedro, ya que en algunos casos se producen acumulaciones de negativos de bisagra, y en otros el ángulo obtenido por la extracción es demasiado abrupto para continuar el proceso de talla. Probablemente, debido a esto se descartó la pieza.

Las piezas restantes pueden adscribirse, como se dijo, a los procesos de manufactura de puntas de proyectil. La dispersión de las variables métricas (ancho, largo y espesor total, así como ancho y largo de pedúnculos de la totalidad de los artefactos bifaciales, ya sea preformas o instrumentos terminados (Figura 6), da cuenta de dos grupos de medidas, que no se correlacionan con los estadios de reducción ${ }^{6}$. Si en el sitio estuviera representado únicamente un tipo de cadena operativa, sería esperable registrar, a mayor estadio de reducción, menores dimensiones de las piezas. Al no cumplirse esta expectativa, interpretamos que estos valores representan la selección de distintos tamaños de soportes, lo que, como se verá a continuación se asocia a la obtención de productos de características métricas acordes.
Un primer tipo de cadena operativa corresponde a la confección de puntas tipo periodo IV. El único ejemplar terminado que se registró (Figura 7a) presenta algunas características morfológicas adecuadas para su utilización como punta de dardo: ángulo del ápice en vista plana superior a $45^{\circ}$, pedúnculo de diámetro mayor a $10 \mathrm{~mm}$ y aerodinamia imperfecta con una superficie de contacto media. No obstante, la superficie de refuerzo es baja, lo que es más coherente con un uso como arma de mano, lo que podría ser consecuencia de su reactivación.

El empleo de lascas como formas base, se encuentra evidenciado en dos casos, en los que es observable una porción de la cara reversa que aún no ha sido cubierta por extracciones. La menor cantidad de extracciones en el reverso puede explicarse por el aprovechamiento de la convexidad natural de esta superficie, aunque hay que considerar que la mayoría de los casos, tanto preformas como la pieza terminada, se encuentran totalmente cubiertos de lascados. Las primeras operaciones de modificación del soporte registradas, incluyen lascados relativamente invasivos (alcanzan o sobrepasan la mitad de la pieza), cuyas huellas han sido borradas por las extracciones posteriores, por lo que no es posible determinar su orden o técnica de obtención. Debido a su carácter invasivo, particularmente en relación a las extracciones posteriores, probablemente correspondan a una operación de adelgazamiento de la pieza. A continuación, se registran operaciones de delineación de la base, por presión y alternando el trabajo de las caras. No obstante este orden secuencial

7 Mide $50^{\circ}$.
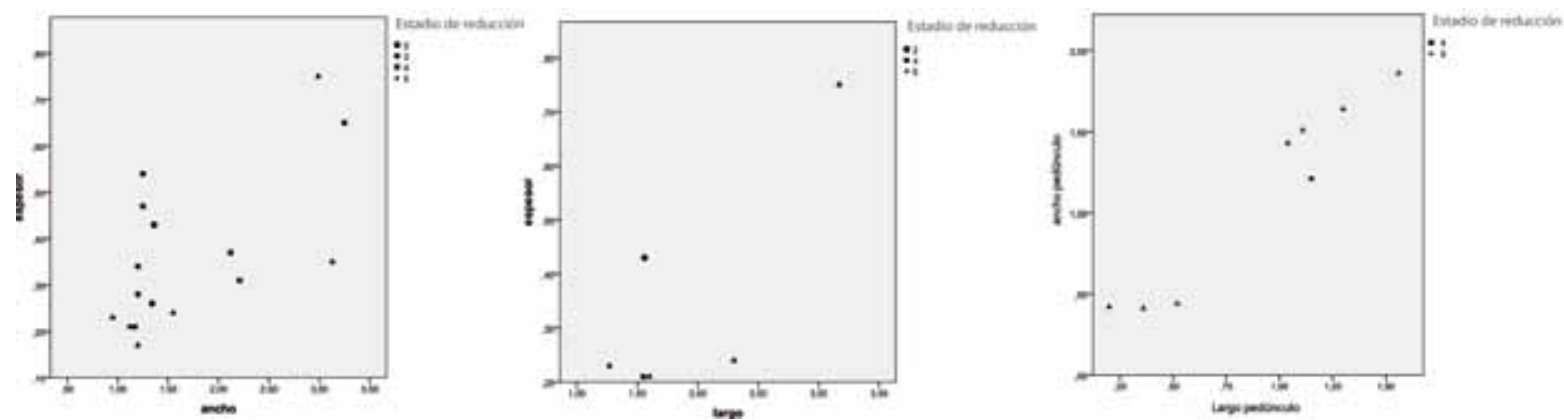

Figura 6. Largo, ancho y espesor total (en $\mathrm{cm}$ ), y largo y ancho de los pedúnculos de los artefactos bifaciales según estadio de reducción. En los dos primeros gráficos, sólo se consideraron los casos en los que fuera posible tomar las medidas máximas (ancho y largo). En el caso de las medidas de los pedúnculos, sólo las piezas que conservan el pedúnculo completo. 
Tabla 2. Representatividad tecnológica de las variedades de materia prima (nódulos analíticos mínimos) utilizadas en cadenas operativas de reducción bifacial.

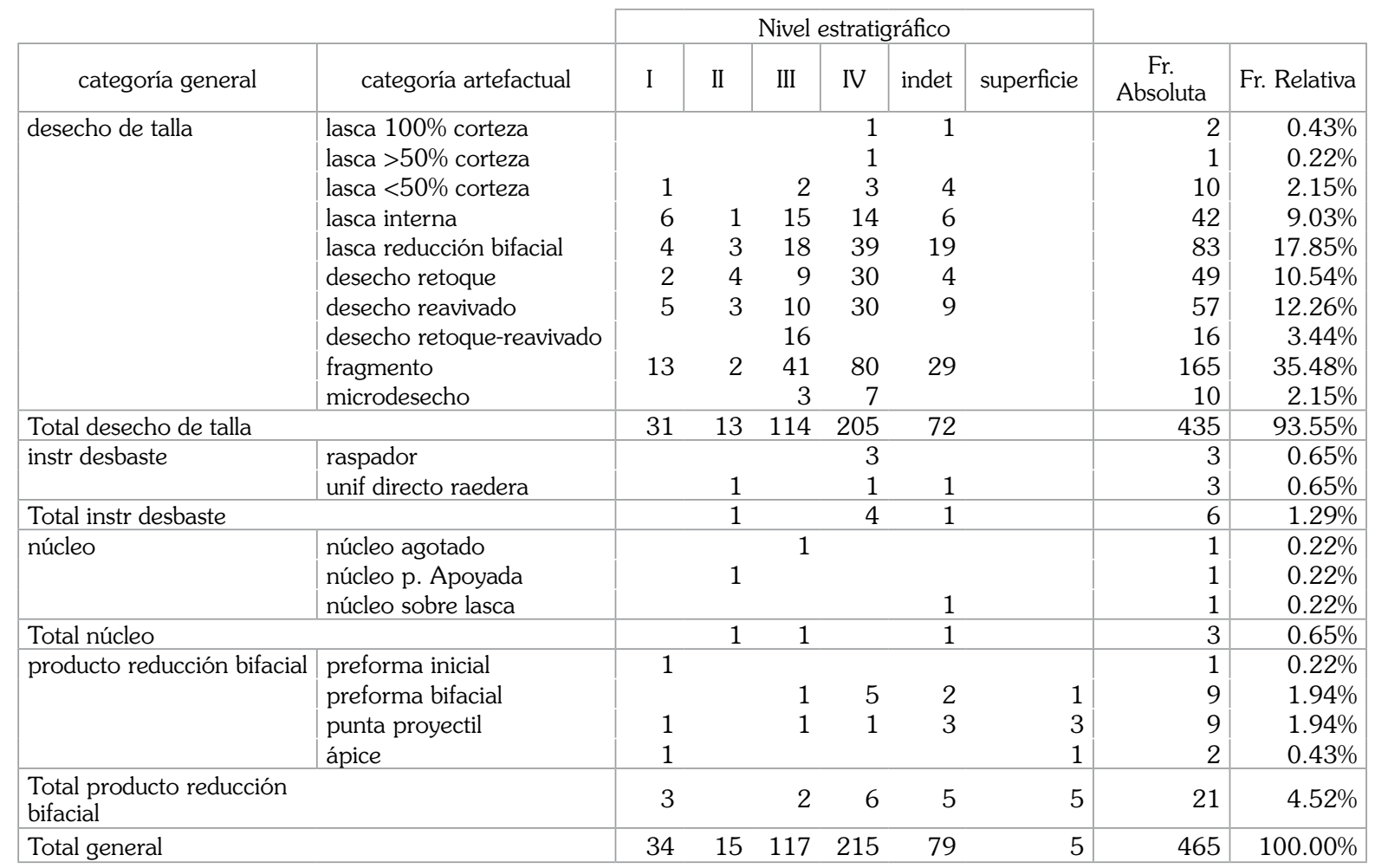

se observa en muy pocos casos, dada la presencia de retoques posteriores en la mayoría de las piezas.

Una vez obtenido el espesor deseado, y luego de la delineación de la base, se procede a trabajar únicamente los bordes, mediante extracciones más cortas por presión o percusión blanda. Con esto se delinean los bordes convergentes y se acentúa la convexidad de la sección, modificándose las dimensiones y morfología sin una reducción mayor del espesor (Figura 7). En general, este proceso se lleva a cabo en forma continua, un borde a la vez, y con un trabajo separado de las caras, dado que la principal forma de preparación de plataforma parece ser el facetado de la cara opuesta, ubicando las plataformas por debajo del plano de equilibro bifacial.

Con posterioridad se trazan pedúnculo y aletas por presión, generalmente trabajando ambas caras simultáneamente o alternando series cortas, utilizando como plataforma los lascados de la cara opuesta o la arista de intersección de los mismos. Como última etapa de manufactura, la intersección de las extracciones de los bordes es en ciertos casos también trabajada por presión, lográndose una arista más recta.

Un segundo grupo de artefactos, se asocia a la manufactura de puntas tipo periodo $\mathrm{V}$ (Figura 8). Las 4 piezas que podemos considerar como terminadas, pudieron potencialmente funcionar como puntas de flecha, en base a los criterios enunciados previamente: presentan un diámetro del pedúnculo inferior a $1 \mathrm{~mm}$, ángulo del ápice visto de frente menor o igual a $45^{\circ}$, aerodinamia normal (de acuerdo a la simetría de los bordes y secciones y al tamaño de la superficie de contacto que es pequeña en todos los casos) y módulo de refuerzo bajo. Al menos 6 piezas dan cuenta del uso de lascas como formas base. En la mayoría de los casos, el soporte es trabajado enteramente por presión, si bien se requieren varias series, y en los instrumentos terminados son pocos los casos en los que puede reconocerse el soporte. Si bien hay una relativa variabilidad en la manera en la que se ejecutan estas extracciones, también son observables ciertas regularidades. El soporte utilizado tiende a orientarse de manera que el eje 

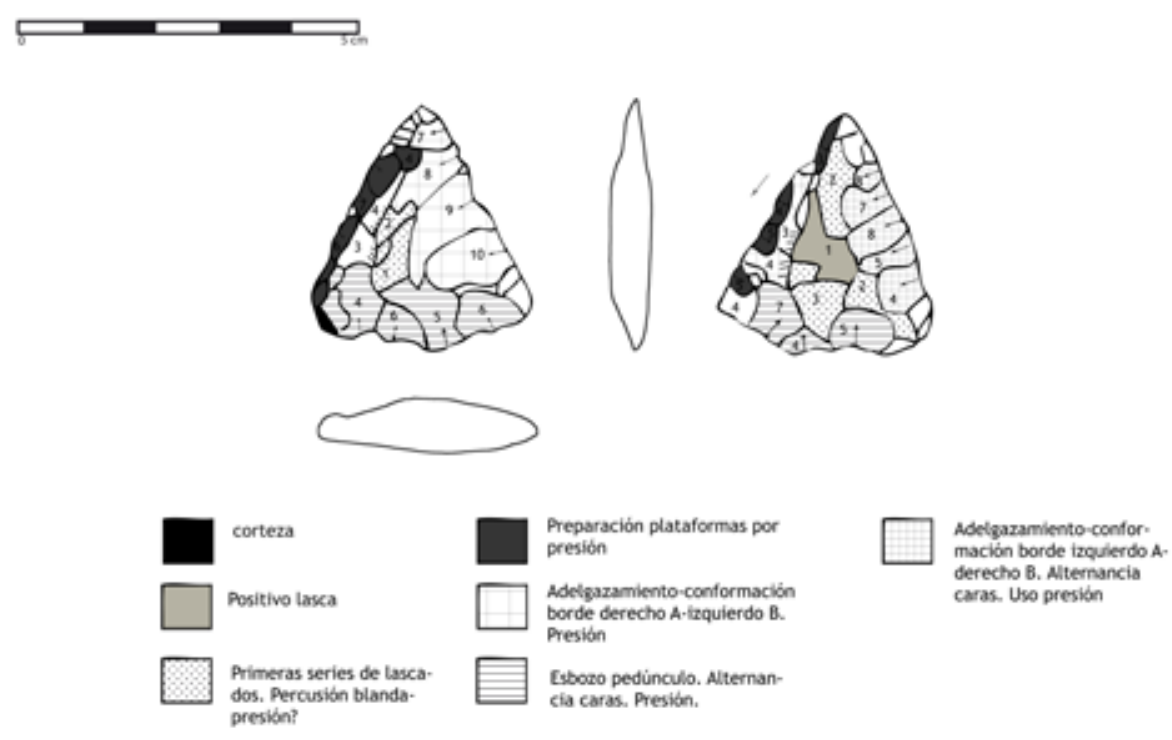
derecho B. Aiternancia caras. Uso presion

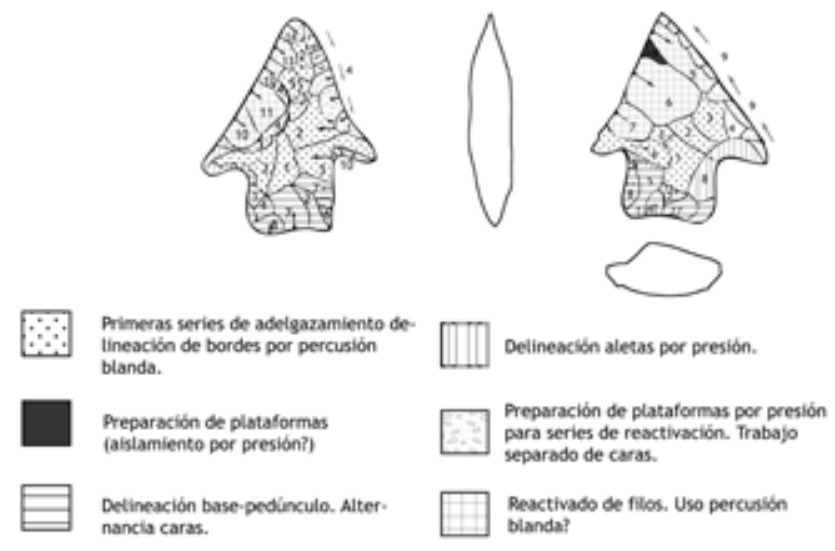

Fig. 7. Esquemas diacríticos de puntas tipo Fell IV.

tecnológico coincida con el eje funcional de forma tal que la porción proximal del instrumento se factura en el sector de la lasca que incluye el talón. En cuanto al orden de las extracciones, en la mayoría de los casos, se comienza por un trabajo sumario de la cara reversa, o bien trabajando ambas caras simultáneamente, ubicando las plataformas por debajo del plano de equilibrio bifacial. Esto permite la creación de un borde susceptible de ser usado como plataforma y la eliminación de los rasgos tecnológicos del reverso. A continuación se realizan una o más series de adelgazamiento por presión, dependiendo del espesor de la pieza, lográndose un contorno de tendencia oval, delineándose al mismo tiempo la base. Luego, se realiza una nueva serie de extracciones desde los bordes, lográndose la morfología triangular del limbo, en general un borde a la vez y trabajando las caras separadamente, en los casos en que puede determinarse. Estos dos tipos de extracciones se obtienen predominantemente a partir de plataformas preparadas por el facetado de ambas caras y posterior desgaste, aislando las plataformas y ubicándolas más cercanas al plano de equilibrio bifacial. La cantidad de series de lascados puede variar, dependiendo del tamaño del soporte elegido, aunque por lo general no se trata de más de dos series. Las 
últimas operaciones registradas corresponden a la manufactura del pedúnculo y las aletas por presión, sin que sean observables recurrencias en el orden de realización de las extracciones. Además, tres casos presentan extracciones interpretadas como de reactivación, debido a que producen asimetrías en la pieza o rompen con el patrón de orden de los lascados a los que se sobreponen.

\section{Subproductos de talla bifacial}

El análisis de las lascas y fragmentos derivados de operaciones de talla bifacial otorgan otros datos importantes en relación a varios aspectos de las cadenas operativas de manufactura:

- Técnicas de talla. En todos los estratos y materias primas se detectaron lascas de reducción bifacial con atributos asociados al uso de percusión blanda (Pelegrin 2000). Estas corresponden al 47\% del total. En particular destaca la presencia de este tipo de lascas en el nivel estratigráfico I en el que la totalidad de las puntas corresponden al tipo período $\mathrm{V}$, que por lo general presentan únicamente un acabado por presión. Esto indica el uso inicial de percusión blanda, al menos en algunos casos, en la confección de este tipo de artefactos. Por otro lado, también se detectó la presencia minoritaria (9\%) de lascas de reducción bifacial probablemente obtenidas por percusión dura, principalmente en los niveles III y IV, lo que da cuenta del uso de esta técnica en ciertos casos para manufacturar puntas de proyectil. Cabe destacar que todas corresponden a grupos de materia prima que incluyen artefactos con presencia de corteza, por lo que posiblemente se privilegió el uso de esta técnica sobre soportes en estadios menos avanzados de reducción.

- Operaciones de preparación de plataforma: Se observan diferencias en los talones de las lascas a lo largo de la secuencia de ocupación. Los talones facetados predominan en los niveles III (35\%) y IV (40\%), mientras que en los niveles restantes, los planos son los más abundantes (cerca del 30\%). Otras operaciones de preparación de plataforma se registran en forma similar en todos los estratos, incluyendo el facetado del borde adyacente al talón (14\%), el facetado seguido de abrasión (5,6\%),y la abrasión del borde (4,5\%).

- Número y tipo de negativos en el anverso de las lascas y fragmentos. En este aspecto se observan algunas diferencias diacrónicas, ya que en los niveles

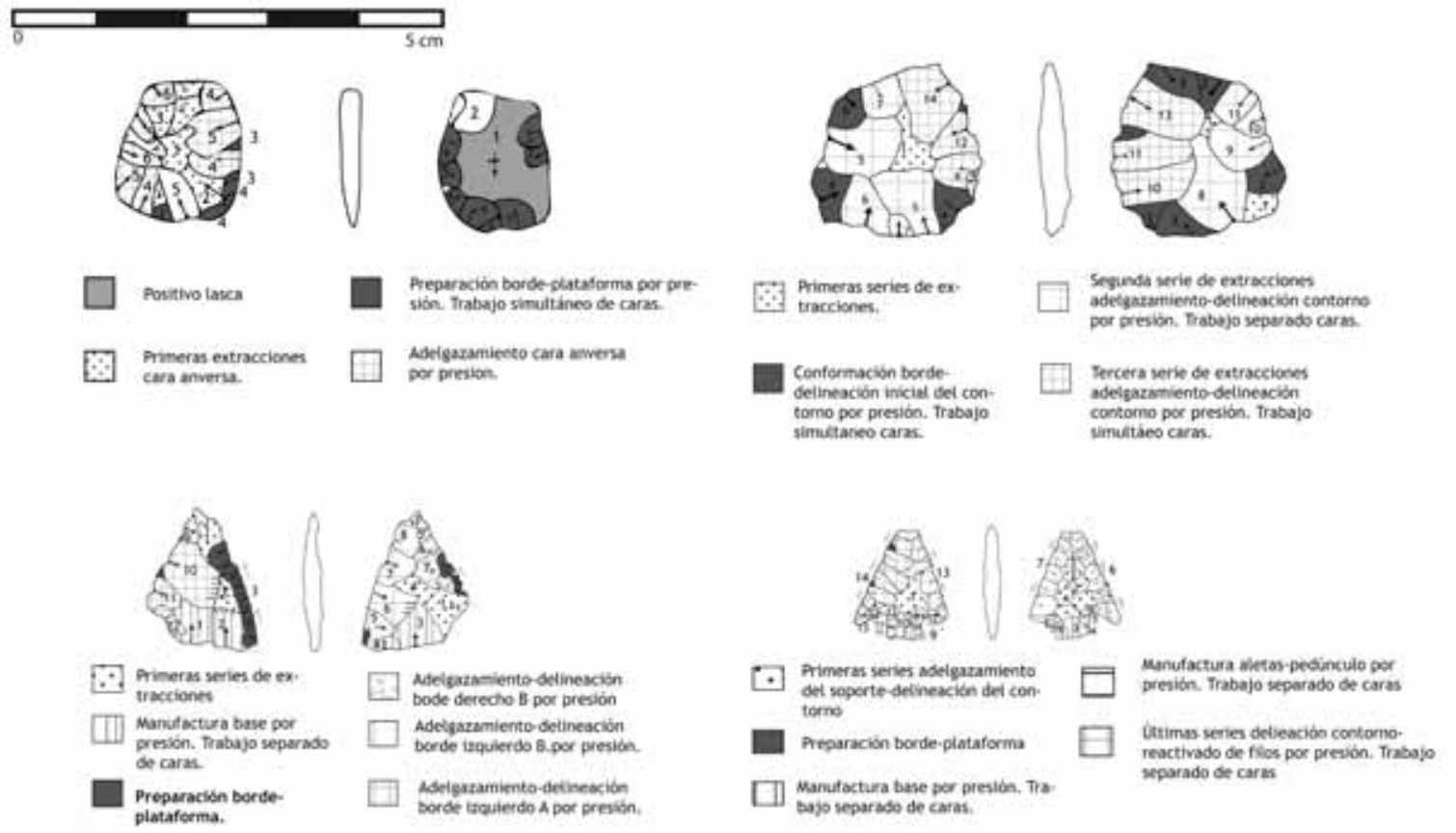

Fig. 8. Esquemas diacríticos de puntas tipo Fell V. 
III y IV predominan los negativos de orientación centrípeta (54\% y $20 \%$ respectivamente), mientras que en las ocupaciones más tardías, los negativos paralelos unidireccionales son mayoritarios (35\%).

\section{DISCUSIÓN}

\section{Métodos y técnicas de talla}

Como se dijo, encontramos dos tipos de cadena operativa de reducción bifacial en el sitio, ambas conducentes a la producción de puntas de proyectil, pero de distintas características (fundamentalmente métricas), que se traducen en modos de uso potenciales distintos (puntas de dardo versus puntas de flecha). Si bien los métodos de talla presentan una relativa variabilidad interna en determinados aspectos, son bastante similares entre sí, y las principales diferencias observadas en cuanto a la forma en la que se ejecutan las distintas secuencias operativas tienen que ver con las características de los soportes escogidos. De esta forma, un problema interpretativo básico para el análisis fue asociar la variabilidad de tamaño de los instrumentos a distintos tipos de cadena operativa, o a distintos momentos de un mismo tipo de secuencia de manufactura (el considerar por ejemplo una punta como preforma inicial de tipo periodo $\mathrm{V}$, o una en estado más avanzado de confección del tipo IV). A pesar de este problema, como se expuso en los resultados, resulta evidente que ambos tipos de instrumento son el resultado de cadenas operativas distintas, esto es, las diferencias entre los instrumentos obtenidos no corresponden a distintos estadios de reducción, sino que a objetivos distintos. No obstante los procedimientos técnicos específicos para alcanzar estos objetivos, son similares.

En cuanto a las materias primas utilizadas, se observa una menor variabilidad de rocas escogidas para la reducción bifacial en relación a otras actividades de talla, lo que da cuenta de una cierta selección condicionada principalmente por criterios de calidad. Otros criterios, como las formas y tamaños de presentación son difíciles de evaluar, ya que las fases de obtención de los soportes utilizados están muy poco representadas en el sitio. No obstante, el hecho de que se utilicen principalmente lascas de distintas dimensiones, apoya la hipótesis de que no se trataría de un factor crítico. Junto con esto, cabe destacar que no se detectaron diferencias en el tratamiento de las distintas materias primas. Como se dijo, éstas se asocian sobre todo a las distintas características de los soportes.

Los soportes utilizados son variables, aunque hay una tendencia a utilizar lascas de dimensiones relativamente cercanas a los productos finales ${ }^{8}$, que por lo general se extraen fuera del sitio. No pudo determinarse si se obtienen por algún método recurrente de desbaste, dada la escasa representación de estos momentos de las cadenas operativas, siendo un aspecto a evaluar a futuro. Es principalmente en relación al tamaño del soporte escogido que varían las formas de ejecución de las secuencias operativas, sobre todo en cuanto a la cantidad de series de extracciones necesarias para lograr el objetivo buscado, y a las técnicas de talla. Así se observó el uso de percusión dura, e incluso de percusión apoyada en algunos eventos de talla presumiblemente de puntas tipo periodo IV, en los que los soportes eran de mayor tamaño (incluyendo un posible guijarro) y con presencia de corteza. El uso de percusión blanda, sugerido principalmente por la presencia de lascas de reducción bifacial obtenidas por esta técnica, está muy representado en eventos de talla asociados a puntas tipo periodo IV, pero también en algunos casos de puntas periodo $\mathrm{V}$, si bien se trata de pocos casos. Estos últimos podrían corresponder a casos en que se seleccionaron soportes de dimensiones (probablemente sobre todo en relación al espesor) mayores a lo habitual, ya que la mayoría de las puntas tipo Ona registradas se manufacturan sobre lascas de espesor casi idéntico al del producto final que son trabajadas directamente por presión.

El uso de la técnica de percusión, para la manufactura de ambos tipos de punta, se asocia, de acuerdo a la interpretación de los esquemas diacríticos y las agrupaciones de eventos de talla, al adelgazamiento (sensu Aschero y Hocsman 2004) del soporte y en menor medida a la modificación del contorno. Con posterioridad, se modifica el contorno por presión delineándose la base y los bordes, lo que en algunos soportes de menor espesor en la confección de puntas tipo Ona, se realiza sin llevar a cabo el adelgazamiento previo. Luego, en ambos casos, se registran operaciones de delineación de los bordes, y finalmente de las aletas y pedúnculo,

8 Es necesario considerar en esta apreciación que el uso de lascas como formas base es más fácil de detectar que el de otros soportes. 
nuevamente por presión. Encontramos entonces que ambos tipos de cadena operativa se componen de etapas similares, que tienden a realizarse en el mismo orden, y que sus diferencias se asocian sobre todo a los tamaños de los soportes, que varían en función del tamaño del producto final ${ }^{9}$.

Por su parte, la manera específica en la que se ejecutan estas distintas secuencias es muy variable en cuanto al orden de las extracciones tanto bifacial como a nivel de una misma cara, y en menor medida, a las formas de preparación de plataforma. En relación a éstas últimas, se detectaron algunas tendencias en cuanto a su posición en relación al plano de equilibrio bifacial (sensu Inizan et al. 1995), pero son muy pocos los casos en los que esto es observable. De esta forma, las secuencias operativas tienden a ejecutarse en un mismo orden para la manufactura de ambos tipos de punta, pero la manera en la que estas se llevan a cabo es variable: trabajando las caras simultánea o separadamente, por menos o más series de lascados, preparando las plataformas por facetado de una o ambas caras, por abrasión, o por combinaciones de los distintos procedimientos.

\section{Variabilidad diacrónica}

A lo largo de toda la secuencia ocupacional, se realizan similares actividades de talla lítica, siendo mayoritarias aquellas asociadas a la confección de instrumentos, las de manutención y reactivación de filos, y de reemplazo de cabezales líticos; estando menos representadas las actividades asociadas a las primeras etapas de las cadenas operativas de manufactura, tales como la obtención de lascas. Esto da cuenta de una mantención en la funcionalidad de sitio, lo que es concordante con los datos existentes de otras materialidades (Massone et al. 1993). A la vez, se utilizan las mismas materias primas representadas en forma similar. Esto último es similar para el caso de la reducción bifacial, ya que en todos los niveles predomina el uso de sílices, rocas ígneas félsicas y RGFO para estas operaciones. Además estas ingresan en su gran mayoría bajo forma de lascas con o sin corteza, que habrían sido obtenidas fuera del sitio.

9 Obviando la relativa variabilidad en los soportes escogidos en cada tipo de cadena operativa, es claro que para manufacturar puntas tipo Ona se seleccionan formas base más pequeñas que para facturar puntas tipo periodo IV.
No obstante, como se mencionó, sí se encuentran discontinuidades en los productos buscados.

En descripciones previas del material (Massone et al. 1993), se constata un cambio entre los niveles IV y III, en los que las puntas corresponden al tipo periodo IV, y los estratos superiores, en los que los instrumentos bifaciales corresponden únicamente a puntas tipo Ona. En este análisis, encontramos además diferencias en los desechos de talla que refuerzan esta observación. Si bien no se observaron diferencias en sus tamaños, los desechos de los niveles más tempranos presentan mayor proporción de talones facetados, y negativos más complejos en el anverso, mientras que en aquellos de los niveles I y II predominan los talones planos y los negativos paralelos, por lo general en el mismo sentido del eje tecnológico. Estos datos pueden interpretarse como resultado de secuencias de reducción más largas, como aquellas asociadas a la confección de puntas tipo Bird IV en las ocupaciones más tempranas, y más cortas, como las asociadas a la manufactura de puntas tipo Ona, en las ocupaciones más recientes.

Lógicamente, esto no implica que estos esquemas sean excluyentes y que no puedan haber coexistido en algún momento, tal como se ha registrado para el continente. Además, encontramos el ya mencionado problema de adscribir a una u otra cadena operativa los distintos instrumentos (sobre todo considerando que se obtienen por métodos de talla muy similares), así como la presencia de algunas piezas que no se ajustan a ninguno de los dos parámetros. Junto con esto, en el nivel IV, hay algunos indicios de la presencia de ambos esquemas. Se trata de agrupaciones de desechos de talla bifacial que en base al criterio de homogeneidad de materia prima, podrían asociarse a la manufactura de puntas de proyectil de tamaño pequeño provenientes de limpiezas de perfil. No obstante, sin tener claras las proveniencias estratigráficas, y sin la realización de ensamblajes, esto no puede comprobarse.

Entonces, y sin que esto implique la posibilidad de coexistencia en otros contextos, sí encontramos un cambio diacrónico en la representación de cadenas operativas de talla bifacial en el sitio. Considerando las diferencias en los productos buscados en ambos esquemas de talla, esto puede ser el resultado de la adopción del arco y la flecha como principal arma de caza en la zona; los esquemas de manufactura asociados a puntas de menor tamaño, de las cua- 
les las cuatro que podemos considerar terminadas presentan características concordantes con este tipo de utilización, se encuentran preferentemente representados en los dos niveles más recientes de la secuencia. Sin embargo, es necesario tener en cuenta que se trata de pocos casos, y que no se consideraron todos los criterios necesarios para la adscripción funcional de los cabezales líticos, en particular en lo referente a las características de las materias primas (Ratto 2003).

\section{CONCLUSIONES}

Los instrumentos bifaciales de los niveles tardíos del sitio Tres Arroyos 1, corresponden a puntas de proyectil pedunculadas con aletas pequeñas $y$ grandes, que es posible describir como tipos Fell V y Fell IV. Éstas, de acuerdo a sus características morfológicas y métricas, tienen probablemente usos potenciales diferentes, y el análisis indica que se obtienen mediante cadenas operativas también diferentes. Además, se encuentran representadas diferencialmente a los largo de la secuencia ocupacional, lo que da cuenta de una discontinuidad en los productos buscados mediante reducción bifacial que podría estar asociada, dadas sus características morfofuncionales, a un cambio en las tecnologías de caza utilizadas, cuyo alcance deberá ser evaluado abarcando una mayor cantidad de sitios. A la vez, esto puede tener una serie de implicancias (Prieto 1989-90) que deberán ser discutidas utilizando distintas líneas de evidencia.

Ahora bien, aunque los dos tipos de puntas se manufacturan por cadenas operativas diferentes, el método aplicado es casi el mismo, si lo definimos en base a las secuencias operativas presentes y su orden de ejecución. Las distintas técnicas utilizadas en ambos esquemas, se asocian a los distintos tamaños de los soportes escogidos, que en ambos casos tienden a ser lascas de tamaños cercanos a la de los productos finales. Si bien la muestra analizada es pequeña, y además encontramos bastante variabilidad en la aplicación de estos métodos de talla, estas recurrencias pueden representar decisiones tecnológicas análogas, a pesar del cambio en los productos buscados. En ambas situaciones, en los casos en los que pudo determinarse (8 de 21) se privilegió el uso de este tipo de soportes, existiendo una variedad de opciones, y las secuencias operativas se ejecutaron en un determinado orden ${ }^{10}$. En este sentido encontramos una continuidad en los métodos de reducción bifacial, sin distinción de materias primas, aunque haya un cambio en los productos buscados que debe tener un correlato importante en las conductas de estas poblaciones.

A la vez, como se dijo, hay una importante variabilidad interna en la forma de ejecución de los métodos, en la que no se encontraron patrones reconocibles, pero que da cuenta de cómo mediante distintos procedimientos pueden obtenerse resultados análogos. Dicha variabilidad puede asociarse a distintos factores, tales como algunas particularidades de las materias primas o de los soportes, o preferencias personales.

Ampliar la muestra de análisis permitirá a futuro determinar hasta qué punto los métodos aquí identificados, y en particular las recurrencias interpretadas como decisiones tecnológicas, son representativos de las poblaciones fueguinas del Holoceno Tardío. A la vez, el explorar su distribución espacial puede, junto a otras líneas de evidencia, dar cuenta de distintos grados de interacción entre poblaciones, lo que es de particular importancia dados los problemas previamente reseñados en torno a la variabilidad y distribución de las puntas de proyectil bifaciales pedunculadas.

\section{AGRADECIMIENTOS}

Al proyecto Fondecyt 1060020 y a todos sus participantes. A Flavia Morello y Donald Jackson, por su ayuda a lo largo del análisis, y a los evaluadores de este trabajo, por sus útiles comentarios y sugerencias.

\section{BIBLIOGRAFÍA}

ANDREFSKY, W 2009. The analysis of stone tool procurement, production and maintenance. Journal of archaeological research 17 (1): 65-103.

10 No obstante, aparentemente habría una variabilidad mayor para la fabricación de puntas de tamaño mayor (tipo Bird IV), manifestada en la presencia de una pieza bifacial trabajada por percusión dura (si bien esta podría ser también una preforma de otro tipo de instrumento no registrado en el sitio), y de algunas lascas de reducción bifacial obtenidas por esta técnica en los niveles III y IV. Esto estaría dando cuenta del empleo de soportes de mayor tamaño. 
ARAGON, E. Y N. FRANCO 1997. Características de rocas para la talla por percusión y propiedades petrográficas." Anales del Instituto de la Patagonia 25: 187-199.

ASCHERO, C., Y S. HOCSMAN 2004. Revisando cuestiones tipológicas en torno a la clasificación de artefactos bifaciales. En Temas de Arqueología: Análisis lítico. A. Acosta, D. Leponte y M. Ramos compiladores. Buenos Aires.

BIRD, J 1938. Antiquity and migrations of the early inhabitants of Patagonia Geographical Review XXVIII: 250-275. 1993. Viajes y arqueología en Chile Austral. Ediciones de la Universidad de Magallanes, Punta Arenas.

BORRERO, L 1979. Excavaciones en el alero "Cabeza de León". Isla Grande de Tierra del Fuego. Relaciones (Nueva Serie) 13: 255-271.

1986. La economía prehistórica de los habitantes del norte de la Isla Grande de Tierra del Fuego. Tesis Doctoral, Universidad de Buenos Aires. MS.

1989-90. Evolución Cultural Divergente en la Patagonia Austral. Anales del Instituto de la Patagonia, Serie Cs. Humanas 19:133-140.

2003. Taphonomy of the Tres Arroyos 1 Rockshelter, Tierra del Fuego, Chile. Quaternary International 109110: 87-93.

CHARLIN, J. 2005. Utilización de materias primas líticas en el campo volcánico Pali Aike (Pcia. de Santa Cruz, Argentina). Una primera aproximación a partir del análisis de núcleos. Werken 7:39-55.

FRANCO N Y L. BORRERO 2003. Mind the gap: technological variations between both sides of the Magellan Strait. Trabajo presentado en el Fifth World Archaeological Congress. Washington.

FRANCO, N, M. CARDILLO y L. BORRERO 2005. Una primera aproximación a la variabilidad presente en las puntas denominadas 'Bird IV'. Werken 6: 81-95.

FRANCO, N., A. CASTRO, M. CARDILLO Y J. CHARLIN 2009. La importancia de las variables morfológicas, métricas y de microdesgaste para evaluar las diferencias en diseños de puntas de proyectil bifaciales pedunculadas: Un ejemplo del sur de Patagonia Continental. Magallania 37(1): 99-112.

GOMEZ OTERO, J 1987. Posición estratigráfica particular de puntas de los períodos IV y V de Bird en el alero Potrok-Aike (Santa Cruz). En: Primeras Jornadas de Arqueología de la Patagonia, ed. por Dirección de Cultura de la Provincia del Chubut, pp. 125-130. Chubut.

HORWITZ, V. D. 1995. Ocupaciones Prehistóricas en el sur de Bahía San Sebastián (Tierra del Fuego, Argentina). Arqueología 5: 105-136.
HUIDOBRO, C. En prensa. Manufactura de instrumentos bifaciales en Marazzi 2. En Actas del XVIII Congreso Nacional de Arqueología Chilena, Valparaíso, 5 al 10 de octubre de 2009.

INIZAN, ML., M. REDURON, H.ROCHE Y J. TIXIER 1995. Technologie de la pierre taillée. CREP (Cercle de Recherches et d'Études Préhistoriques, CNRS, Meudon.

JACKSON, D 2002. Los instrumentos líticos de los primeros cazadores de Tierra del Fuego. Colección Ensayos y Estudios, Ril editores, Santiago.

LARSON, M. L. Y M. KORNFELD. 1997. Chipped stone nodules: Theory, method, and examples. Lithic Technology 22 (1): 4-18.

MASSONE, M 1979. Panorama etnohistórico y arqueológico de la ocupación Tehuelche y Prototehuelche en la costa del Estrecho de Magallanes. Anales del Instituto de la Patagonia, Serie Ciencias Humanas 10: 69-107.

2004. Los cazadores después del hielo. Centro de investigaciones Diego Barros Arana, Ediciones de la Dirección de Bibliotecas y Museos, Santiago.

MASSONE, M., A. PRIETO Y D. JACKSON (1993) Perspectiva Arqueológica de los Selk'nam. Ediciones de la Dirección de Bibliotecas y Museos, Colección de Antropología, Santiago.

MORELLO, F 2005a. Tecnología y método para el desbaste de lascas en el norte de Tierra del Fuego: El testimonio de los núcleos de cabo San Vicente. Magallania 33(2): 29-52.

2005b. Estudio comparativo del material lítico de los sitios Marazzi 32, Punta Catalina 3 y Punta Baxa 7. En: Las ballenas en el mundo Selk'nam. Un enfoque desde la arqueología y otras disciplinas. Informe final Fondecyt 1020004. MS

MORELLO, F, M. SAN ROMAN, R. SEGUEL y F. MARTIN 1998. Excavación en el Sitio Marazzi 2. Sector 2 Terraza Superior (Río Torcido, Bahía Inútil). Primer Avance. Anales del Instituto de la Patagonia, Serie Cs. Humanas, 26:119-126.

NAMI, H 1987. Los bifaces desde una nueva perspectiva analítica y la interpretación de algunos conjuntos bifaciales de Patagonia y Tierra del Fuego. En Primeras Jornadas de Arqueología de la Patagonia (Trelew). Publicación del Gobierno de la Provincia de Chubut, serie humanidades 2: 185-193.

1988. Arqueología experimental, tecnología, artefactos bifaciales y modelos. Estado actual del conocimiento en Patagonia y Tierra del Fuego. Anales del Instituto de la Patagonia, serie Cs. Sociales 18: 157-176. 
PELEGRIN, J 1991. Les savoir-faire: une très longue histoire. Terrain, carnets du patrimoine ethnologique 16:106-113. 2000. Les techniques de debitage laminaire au Tardiglaciaire: critères de diagnose et quelques réflections. Mémoires du Musée de Prehistoire d'Ile de France 7: 73-79.

PRIETO, A 1989-90. Cazadores tardíos en la zona fronteriza del paralelo $52^{\circ}$ sur. El alero Peggy Bird. Anales del Instituto de la Patagonia Serie Cs. Sc. 19: 73-85.

RATTO, N 1991. Análisis funcional de las puntas de proyectil líticas de sitios del sudeste de la Isla Grande de Tierra del Fuego. Arqueología 1: 151-178.

1994. Funcionalidad v/s adscripción cultural: cabezales líticos de la margen norte del estrecho de Magallanes. En: Arqueología de cazadores recolectores. Límites, casos y aperturas, L. Borrero y J.L Lanata compiladores, Arqueología Contemporánea 5, edición especial, Buenos Aires.

2003. Estrategias de caza y propiedades de registro arqueológico en la Puna de Chaschuil (Depto Tinogasta,
Catamarca, Argentina). Tesis doctoral, Universidad de Buenos Aires. MS.

RAMOS, A Y J. MERENZON 2004. Ensamblajes, tecnología lítica y análisis espacial del Primer Componente de Túnel 1. En Temas de Arqueología: Análisis lítico. A. Acosta, D. Leponte y M. Ramos compiladores, Buenos Aires.

RICHTER, J 2001. Une analyse standarisée des chaines opératoires sur les pièces foliacées du Paleolithique moyen tardif. En Prehistoire et approche experimentale, L. Bourguignon, I. Ortega y M.C Frère-Sautot editores. Editions Monique Mergoil, Montagnac.

SORESSI, M Y JM GENESTE 2006. Discussing the history and the efficacy of the chaîne opératoire approach to lithic analysis. A personal view. Presentación en el simposio electrónico Core reduction, chaîne opératoire, and other methods : the epistemologies of different approaches to lithic analysis, 71th annual meeting of the Society for American Archaeology, Puerto Rico (Estados Unidos, 29 de abril de 2006). 
